\title{
Far-Lateral Transcondylar Approach to a Right Cervicomedullary Dural Arteriovenous Fistula of the Posterior Fossa
}

\author{
Roberto R. Rubio ${ }^{1,2,3}$ Ricky Chae ${ }^{1,2}$ Todd Dubnicoff $^{2}$ Ethan Winkler ${ }^{2}$ Adib A. Abla ${ }^{1,2}$ \\ 1 Skull Base and Cerebrovascular Laboratory, University of California, \\ San Francisco, California, United States \\ ${ }^{2}$ Department of Neurological Surgery, University of California, San \\ Francisco, California, United States \\ Address for correspondence Adib A. Abla, MD, Department of \\ Neurological Surgery, University of California, San Francisco, 505 \\ Parnassus Avenue, M780, San Francisco, CA 94143, United States \\ (e-mail: adib.abla@ucsf.edu).
}

${ }^{3}$ Department of Otolaryngology- Head and Neck Surgery, University

of California, San Francisco, California, United States

J Neurol Surg B 2021;82(suppl S1):S43-S44.

\begin{abstract}
Keywords

- cervicomedullary

- dural arteriovenous fistula

- vertebral artery

- far-lateral approach

- transcondylar

Objectives Dural arteriovenous fistulas (DAVFs) at the cervicomedullary junction are uncommon and often accompanied by subarachnoid hemorrhage (SAH). We aim to illustrate in detail the microsurgical procedure for treating a DAVF located at the cervicomedullary junction.

Design We present a two-dimensional operative video that includes clinical history, preoperative imaging, surgical strategy, still images with labels, clinical course, and postoperative imaging.

Setting The microsurgery was performed at an academic medical center.

Participant The patient is a 55-year-old female who presented with SAH, acute onset headache, nausea, and vomiting. Angiography demonstrated right vertebral artery vasospasm and a persistent arteriovenous shunt at the cervicomedullary junction supplied by small perforating arteries of the right vertebrobasilar junction (-Fig. 1).

Main Outcome Measures The patient was placed in the park-bench position with the head turned to the contralateral side. A hockey stick incision was made, followed by a right-side far-lateral transcondylar approach. Indocynanine green videoangiography was performed to help identify the areas of arteriovenous shunting. Multiple clips were placed to interrupt vessels that corresponded to arterial feeders at the level of the C1 and C2 nerve root sleeves (-Fig. 2 ). The dura was closed in a water tight fashion and the posterior fossa was reconstructed with a titanium mesh.

Results Postoperative imaging showed no evidence of continued arteriovenous shunting. The patient was discharged in good clinical condition with an uneventful postoperative course. Conclusion A deep understanding of the microsurgical vascular anatomy is necessary for successful occlusion of a cervicomedullary DAVF.

The link to the video can be found at: https://youtu.be/-LfOcNB05BY.
\end{abstract}

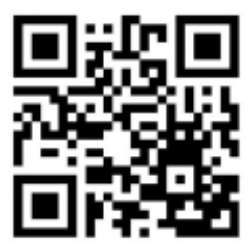

received

March 28, 2019 accepted after revision January 4, 2020 published online November 5, 2020

Conflict of Interest

The authors declare no conflicts of interest.

www.thieme.com/skullbasevideos

www.thieme.com/jnlsbvideos

DOI https://doi.org/ 10.1055/s-0040-1705162. ISSN 2193-6331. (c) 2020. The Author(s).

This is an open access article published by Thieme under the terms of the Creative Commons Attribution-NonDerivative-NonCommercial-License, permitting copying and reproduction so long as the original work is given appropriate credit. Contents may not be used for commercial purposes, or adapted, remixed, transformed or built upon. (https://creativecommons.org/ licenses/by-nc-nd/4.0/)

Georg Thieme Verlag KG, Rüdigerstraße 14, 70469 Stuttgart, Germany 
S44 Far-Lateral Approach to Cervicomedullary Junction Rubio et al.

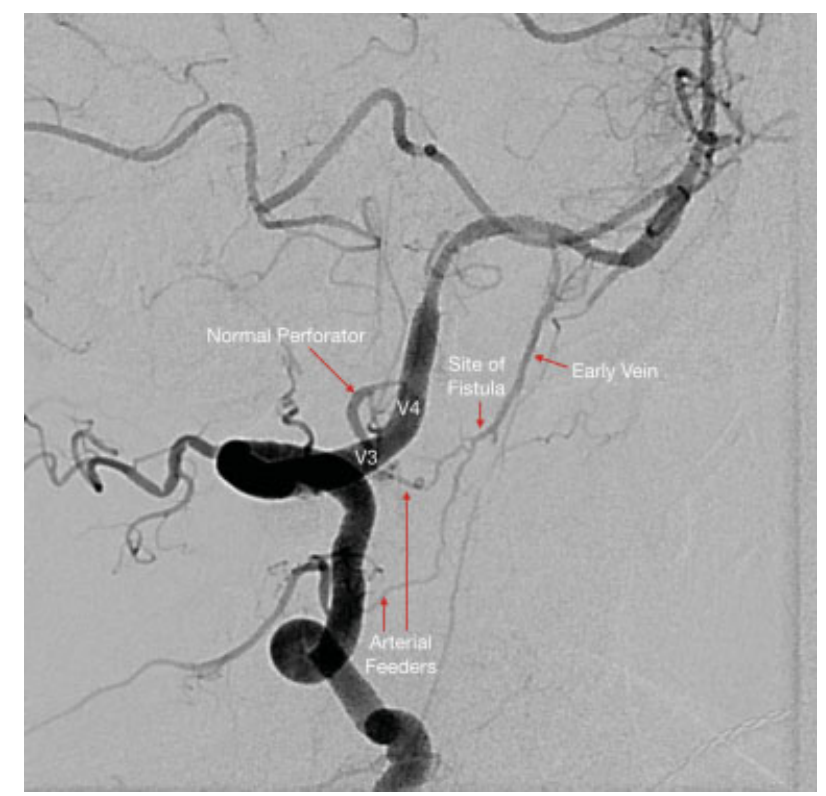

Fig. 1 Perforating arteries of the right vertebrobasilar junction.

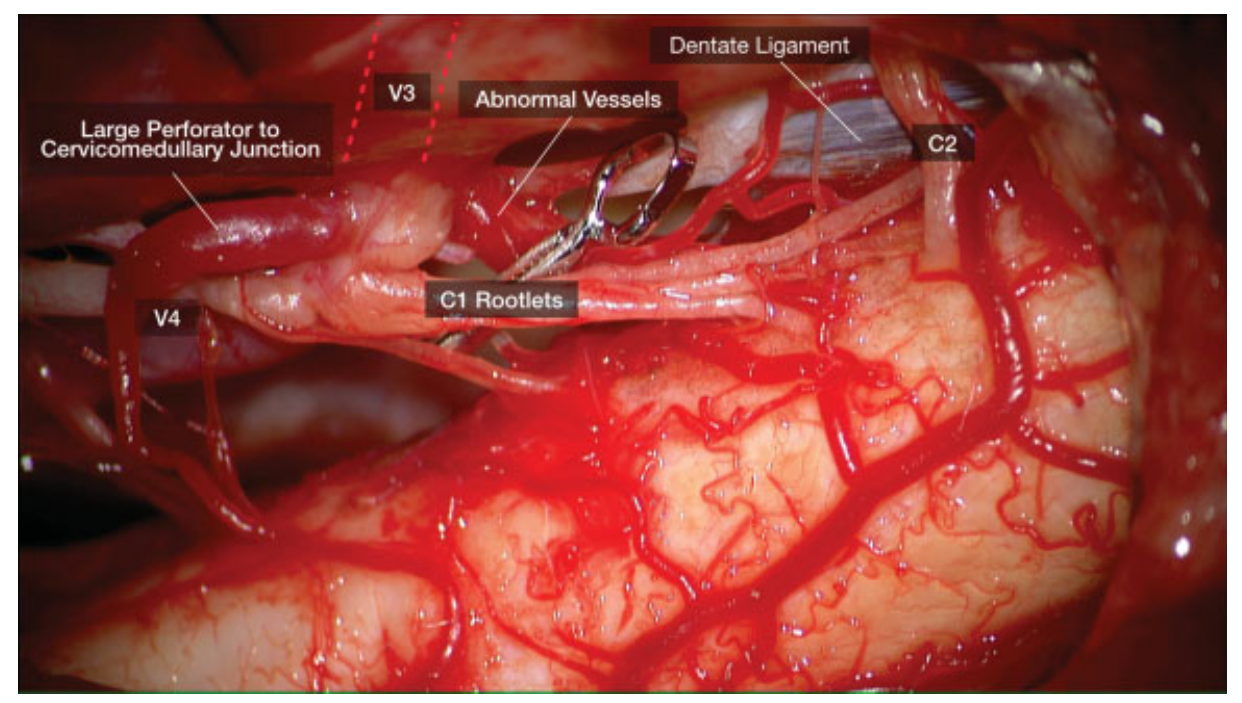

Fig. $2 \mathrm{C} 1$ and $\mathrm{C} 2$ nerve root sleeves. 